Case Report

\title{
Acute Chest Pain in a 70-Year-Old Woman at CNHU-HKM Cotonou: Morbid Association or Diagnostic Wandering
}

\author{
Philippe Mahouna Adjagba ${ }^{1,}$, , Murielle Hounkponou ${ }^{1}$, Arnaud Sonou ${ }^{2}$, \\ Kouessi Anthelme Agbodandé ${ }^{4}$, Salimatou Assani Moutaïrou ${ }^{1}$, Rosaire Bognon ${ }^{1,3}$, \\ Ikram Akinocho ${ }^{1,3}$, Yessoufou Tchabi ${ }^{1}$, Martin Dèdonougbo Houénassi ${ }^{1}$ \\ ${ }^{1}$ Department of Cardiology, Teaching Hospital of Cotonou, Abomey-Calavi University, Cotonou, Benin \\ ${ }^{2}$ Department of Cardiology, Teaching Hospital of Ouémé and Plateau, Abomey-Calavi University, Porto-Novo, Benin \\ ${ }^{3}$ Department of Cardiovascular Rehabilitation and Secondary Prevention, Hospital Center Sud Francilien, Paris, France \\ ${ }^{4}$ Department of Internal Medicine, Teaching Hospital of Cotonou, Abomey-Calavi University, Cotonou, Benin
}

Email address:

dotoup@yahoo.fr (P. M. Adjagba)

${ }^{*}$ Corresponding author

\section{To cite this article:}

Philippe Mahouna Adjagba, Murielle Hounkponou, Arnaud Sonou, Kouessi Anthelme Agbodandé, Salimatou Assani Moutaïrou, Rosaire Bognon, Ikram Akinocho, Yessoufou Tchabi, Martin Dèdonougbo Houénassi. Acute Chest Pain in a 70-Year-Old Woman at CNHU-HKM Cotonou: Morbid Association or Diagnostic Wandering. American Journal of Internal Medicine. Vol. 6, No. 4, 2018 , pp. 56-60. doi: 10.11648/j.ajim.20180604.12

Received: June 4, 2018; Accepted: June 28, 2018; Published: July 21, 2018

\begin{abstract}
Objectives: Challenging differential diagnosis. Background: Acute myopericarditis and ACS STEMI share the presenting triad of acute chest pain, ST segment changes, and elevated cardiac enzymes. Differentiating is not always straightforward. Case Report: We reported the clinical observation of a 70-year-old woman admitted into cardiology intensive care for acute chest pain with electrocardiographic abnormalities suggestive of acute coronary syndrome with ST elevation (ACS STEMI). Pharmacological myocardial revascularization was done. Secondary evolution in the absence of initial coronary angiography is compatible with a myopericarditis of favorable evolution under empiric antibiotherapy. Coronarography performed remotely reveals a significant stenosis of the proximal and middle circumflex. Percutaneous angioplasty was successfully performed. Conclusion: In patients with acute chest pain, ST segment changes and elevated cardiac enzymes, coronary angiography can be useful in differential diagnosis.
\end{abstract}

Keywords: Chest Pain, Acute Coronary Syndrome, Myopericarditis, Angioplasty

\section{Introduction}

Chest pain is a common symptom. It affects $20-30 \%$ of the general population worldwide [1-3]. It accounted for $10.9 \%$ of the reasons for medical consultation at CHUD/ B [4], 2.9\% of the reasons for consultation in the Niamey cardiac services in 2010 [5]. It was reported in $4.1 \%$ of patients admitted for cardiovascular emergencies at CHU Bouaké [6].

In the clinical translation of multiple visceral and parietal disorders, the presentation of chest pain is not always specific and atypical forms can be a source of error. Myopericarditis is one of the clinical diagnosis that often simulates acute coronary syndrome (ACS STEMI) as reported in several series [7-12]. Differentiating acute myopericarditis from ACS STEMI can be challenging because they share the presenting triad of acute chest pain, ST segment changes, and elevated cardiac enzymes.

Diagnostic tools such as coronary angiography, endomyocardial biopsy and cardiac MRI help the clinician to overcome the doubt of diagnosis [8-12]. In low-income countries such as Benin, these tools are not always available, sometimes leading to diagnostic wandering and delay in treatment.

We reported the clinical observation of a 70-year-old woman admitted into intensive cardiac care unit for acute 
chest pain with electrocardiographic abnormalities. She was initially diagnosed as an ACS STEMI, then as a myopericarditis, and finally as a significant coronary stenosis ending with a double angioplasty of the circumflex. We analyzed retrospectively factors explain this diagnostic wandering both clinically and paraclinically.

\section{Case Report}

Interrogatory

The study was performed on a 70-year-old black woman with a medical past history of high blood pressure for 30 years, treated by Losartan and Amlodipine and a type 2 diabetes for 15 years treated with Metformin.

She was admitted to a cardiology practice for chest pain that has been going on for 41 hours. It was a retrosternal seat-type pain radiating to the precordium and in the back, of $8 / 10$ intensity on the digital visual scale which partially yielded under self-medication (Lorazepam and Etifoxine).

There was no dyspnea or fever. The ECG (Figure 1) at the first medical contact was in sinus rhythm with an ST elevation in lateral leads without mirror image.

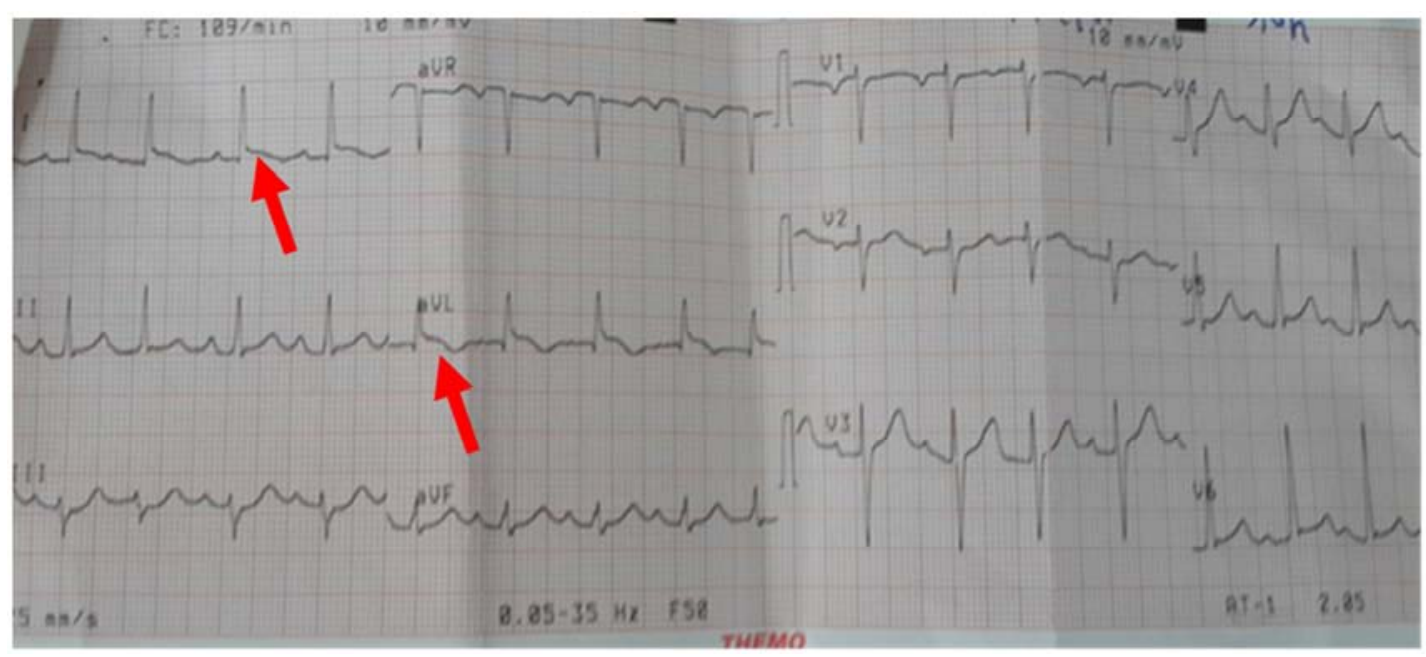

Figure 1. ECG H41, Subepicardial lesion (D1-aVL) with epicardial ischemia (arrows).

She received initial treatment with: Clopidogrel $300 \mathrm{mg}$ (oral), Acetyl salicylic acid 200mg (oral), Enoxaparin $0.5 \mathrm{ml}$ $\mathrm{S} / \mathrm{C}$ (subcutaneous), Atenolol 50mg (oral) and Omeprazole $20 \mathrm{mg}$ (oral).

She was then transferred by medical ambulance to the University Clinic of Cardiology of CNHU-HKM (tertiary center).

Admission Examination and Treatment

On admission, she had a good general and haemodynamic condition. A thoracic pain of intensity $2 / 10$ on the digital visual scale still persisted. Cardiovascular examination was normal.

Weight $=54 \mathrm{~kg} ;$ Size $=1 \mathrm{~m} 58 ; \mathrm{BMI}=21.63 \mathrm{~kg} / \mathrm{m}^{2}, \mathrm{BP}$ $($ right arm $)=113 / 70 \mathrm{mmHg}$, Heart rate $=86 / \mathrm{min}, \mathrm{SpO} 2=98 \%$ in ambient air.

\section{Additional Test}

The ECG performed at the 52nd hour revealed sinus rhythm with an extension of ST elevation in lateral leads (V5-V6) with fine basal q wave, with PQ shift in infero lateral (Figure 2).

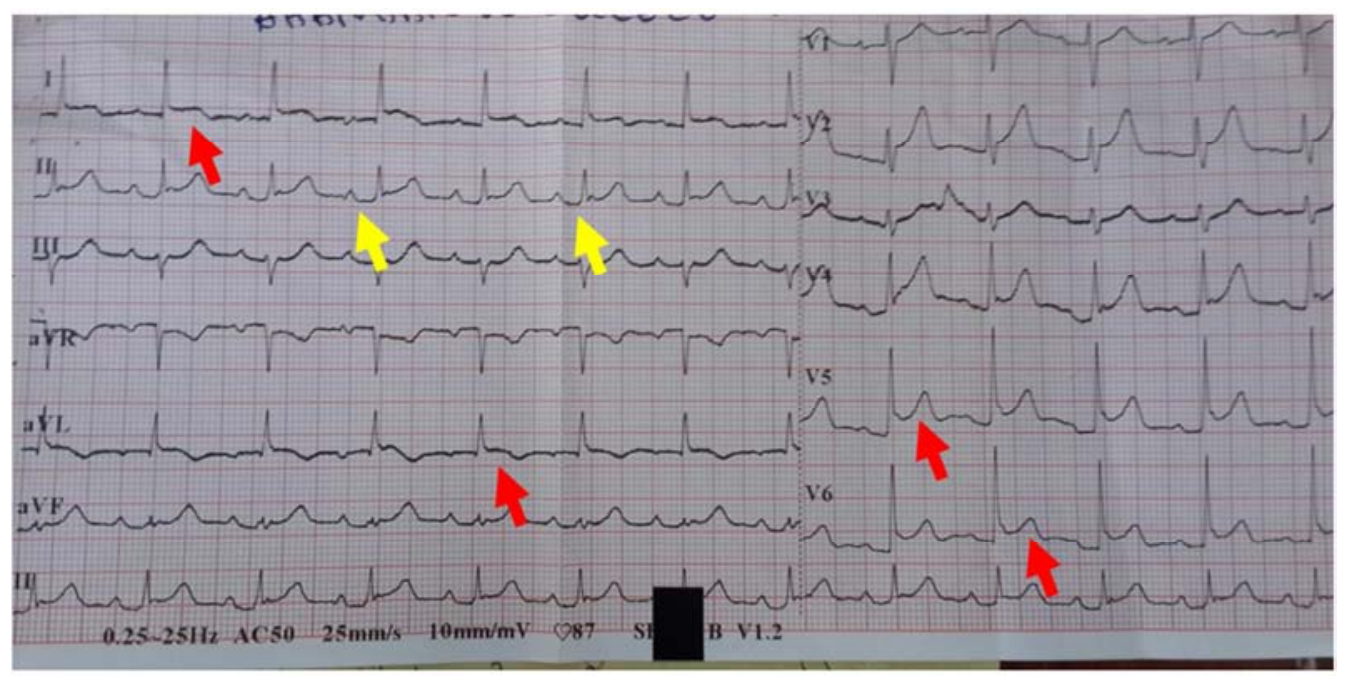

Figure 2. ECG H52, high lateral subepicardial lesion (D1-aVL) with subepicardial ischemia and lateral subepicardial lesion (V5-V6) (arrows in red). PQ sub-shift in infero lateral leads (arrows in yellow). 
Troponin Ic was $3.89 \mathrm{ng} / \mathrm{ml}$ (389 times normal).

Transthoracic Echocardiogram (TTE) found an unextruded left ventricle without hypertrophy with infero lateral and basal hypokinesia and a $45 \%$ left ventricular ejection fraction. There was no pericardial effusion.

The initial diagnosis of acute coronary syndrome with persistent ST elevation (ACS STEMI) was retained and the treatment prescribed in the practice was continued.

\section{Treatment and Evolution}

A secondary aggravation of the pain $(6 / 10$ on the digital visual scale) was noted with an extension of the ST elevation in V3, V4, D2, D3 and aVF. Thrombolysis was decided and performed at the 64th hour after the start of the initial pain with actilysis. There were no clinical or electrical criteria for myocardial reperfusion. There was no externalized bleeding.

The evolution was marked by a complete sedation of the pain, the appearance of a fever with $38-38.5^{\circ} \mathrm{C}$, and a pericardial effusion on the $3 \mathrm{rd}$ day of hospitalization with gradual increase the following days (Figure 3 ). The appearance of a left pleural effusion worsen progressively from the 5th day (Figure 4).

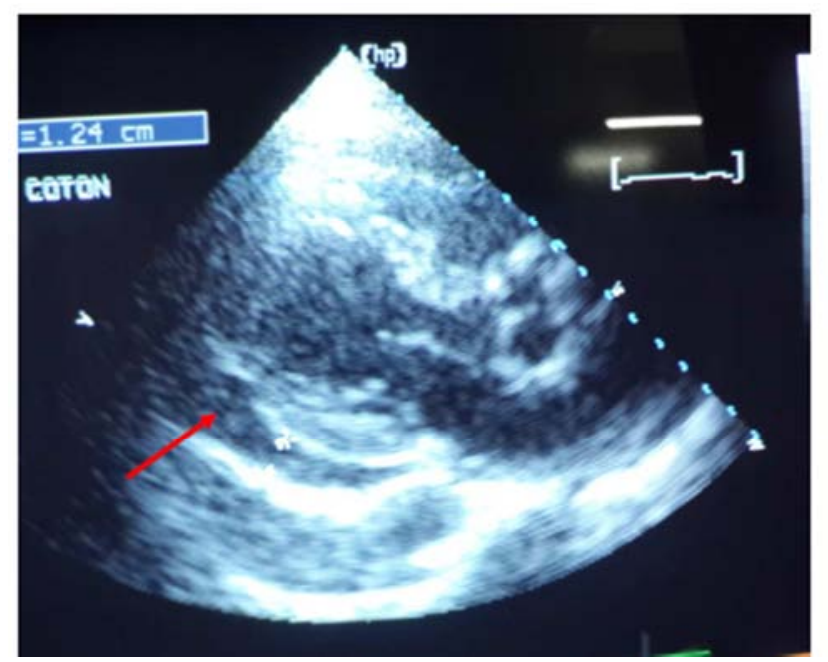

Figure 3. Tran-thoracic echography (TTE), parasternal long-axis incidence, presence of pericardial effusion post fibrinolysis (arrow).

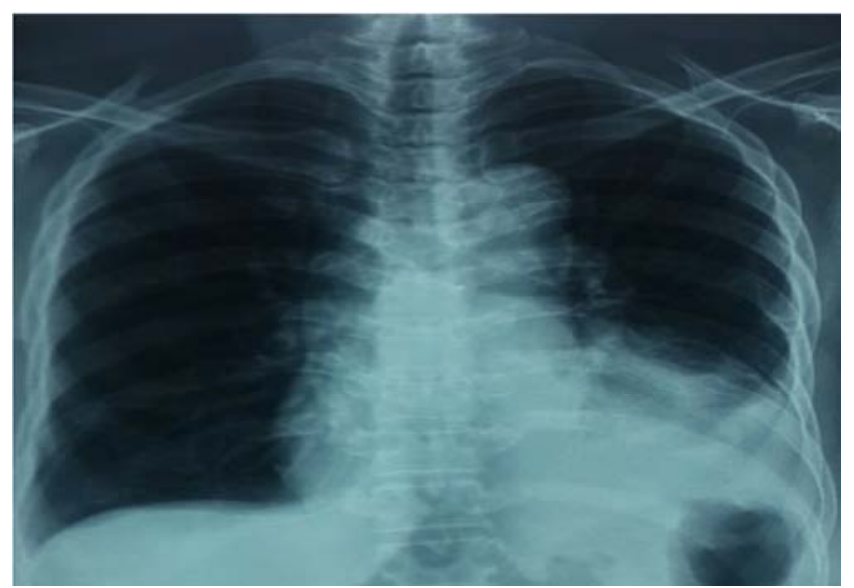

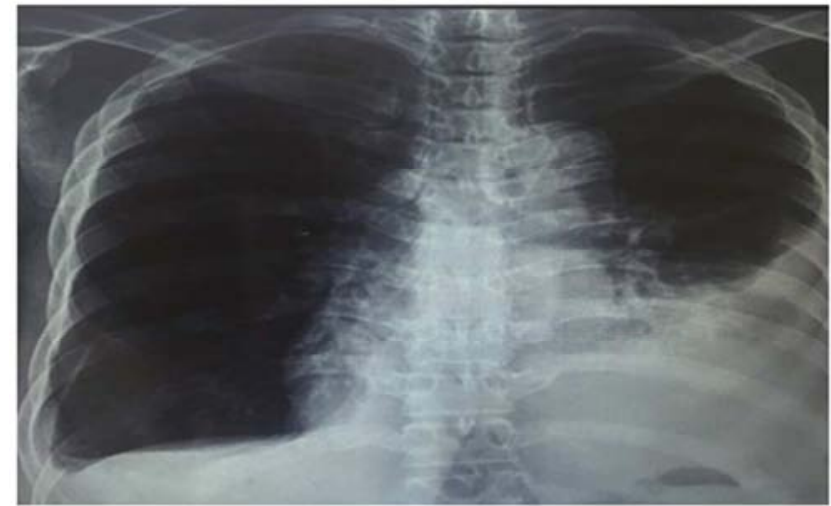

Figure 4. Frontal chest X-ray, left pleural effusion, and blunting of the right costo-diaphragmatic cul-de-sac (Day 5: Left image, Day 14: Right image).

At the Biological Level

1. Troponin Ic remained stable: $3.89 \mathrm{ug} / \mathrm{L}$ at day 1 and 4.01 $\mathrm{ug} / \mathrm{L}$ at day 4 ;

2. CRP decreased from $49 \mathrm{mg} / 1$ on day 1 to $63 \mathrm{mg} / 1$ on day 5 ; 3. The white count increased from $7.8 \mathrm{G} / \mathrm{L}$ on day 1 to 14.4 G/ L on day 5 with predominantly neutrophils;

4. The Hb level had dropped from 10 to $7.8 \mathrm{~g} / \mathrm{dl}$ on D3;

5. Pleural puncture fluid was turbid, rivalta positive, germless with $90 \%$ lymphocytosis.

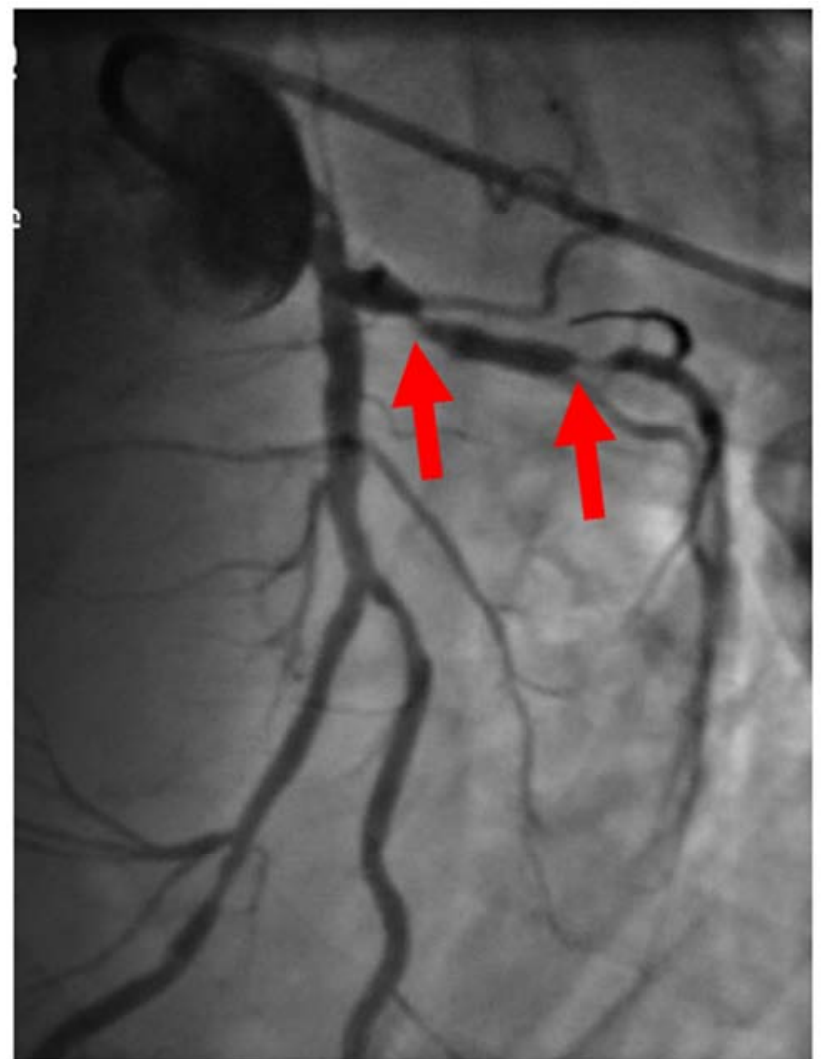

Figure 5. Angiography of the left coronary in LAO45-CR25 incidence. Guide in the circumflex, tight stenosis of the proximal and middle circumflex (arrows).

The diagnosis of myopericarditis simulating ACS STEMI 
was then retained instead of the initial diagnosis. The initial antithrombotic treatment was stopped. Empiric antibiotic therapy with rovamycin and clavulanic acid and amoxicillin has been instituted, as well as an inhibitor of the conversion enzyme.

ST elevation was normalized secondarily with the disappearance of pericardial and left pleural effusions.

A coronary angiogram was performed after 7 months at the Institute of Cardiology of Abidjan and found:

1. Tight stenosis of the proximal and middle circumflex (90\%) (Figure 5);

2. Non-stenosing atheroma of the anterior interventricular and right coronary.

An angioplasty of the proximal and middle circumflex with double stenting (bare stent: TSUNAMI brand) has been successfully performed.

\section{Discussion}

The case report of this patient shows the diagnostic difficulty with atypical chest pain and display diagnostic, wandering successively with an ACS STEMI and then a myopericarditis, and finally a significant coronary stenosis ending with a double angioplasty of the circumflex. Several confounding factors explain this diagnostic wandering both clinically and paraclinically.

Myocarditis can take many clinical forms and those that simulate acute coronary syndrome are not uncommon [7-15].

The two diseases share in common the thoracic pain which in this patient was atypical by its type and in the absence of the conventional irradiations known in the ACS. However, it is extremely rare that myocarditis causes electrical changes concomitant with painful recurrence [8], as was the case in our observation.

Apart from the infectious context, which accompanies myocarditis, clinical features are rarely an aid to diagnosis. Fever is delayed in ACS as was the case in this clinical observation.

Acute myocarditis in its viral form is often the prerogative of a young person without cardiovascular risk factors [8-15]. The patient presented in this article cumulated, outside the age, two major risk factors of atherosclerosis: the high blood pressure and type 2 diabetes. The onset of pain in the presence of these atherosclerotic risk factors with electrical abnormalities legitimizes the initial diagnosis of ACS STEMI in our patient.

Electrically, the location of electrical modifications is also worthless. Several cases of authentic myocarditis show persistent systematized ST elevation [12, 16, 17]. In our patient, the absence of mirrored signs, despite the systematized nature of the initial electrical abnormalities, as well as the extension of these abnormalities that have become secondarily diffuse, and have also led to possible myocarditis.

The biology, common to both pathologies, does not guide the diagnosis with a rise in serum levels of troponin Ic and an inflammatory syndrome as was the case in our patient. The increase in the biological markers of inflammation and a troponin Ic which remained high were all sources of diagnostic error leading to rectifying wrongly the initial diagnosis.

Alteration, rather global than segmental, of left ventricular kinetics in the transthoracic echocardiography (TTE) is not a rule, since lesions may have focal or multifocal distribution or may be summarized as diastolic dysfunction $[12,18,19]$. Note that, in our patient, the segmental kinetic disorders were consistent with the initial electrocardiographic territory.

Coronary angiography was indicated to remove the doubt. It was not feasible in our work context. In cases of myocarditis simulating ACS reported in the literature, diagnostic certainty has been provided by magnetic resonance angiography or endomyocardial biopsy [8-15]. The significant coronary lesions demonstrated during the coronary angiography, carried out at a distance in our patient, were compatible with the initial electrocardiographic territory. Also, the infero lateral and basal seat of the anomalies of the segmental contraction objectified with the TTE.

The presence of pericardial effusion at TTE post-fibrinolysis certainly reflects a haemorrhagic complication with deglobulization as evidenced by a drop of $2.2 \mathrm{~g} / \mathrm{dl}$ of hemoglobin.

\section{Conclusion}

The differentiation between ACS and myopericarditis is essential because of their differences in risk for specific complications, prognosis, and treatment implications. Adequate differential diagnosis is not always a straightforward and not possible by conventional tests. Coronary angiography performed in time would avoid diagnostic wanderings.

\section{Conflicts of Interest}

The authors do not declare any conflict of interest.

\section{Acknowledgements}

The authors thank Professor Roland N'GUETTA of the Abidjan Heart Institute for coronary angiography images.

\section{References}

[1] Ruigómez A, Rodríguez LA, Wallander MA, Johansson S, Jones R. Chest pain in general practice: incidence, comorbidity and mortality. Fam Pract. 2006 Apr; 23 (2): 167-74.

[2] Wong WM, Lam KF, Cheng C, Hui WM, Xia HH et al. Population based study of noncardiac chest pain in southern Chinese: prevalence, psychosocial factors and health care utilization. World J Gastroenterol. 2004 Mar 1; 10 (5):707-12.

[3] Eslick GD, Jones MP, Talley NJ. Non-cardiac chest pain: prevalence, risk factors, impact and consulting--a population-based study. Aliment Pharmacol Ther. 2003 May 1; 17 (9):1115-24. 
[4] Domonhedo A E T. Etude épidémiologique des douleurs thoraciques non traumatiques en milieu médical à Parakou en 2017. [Thèse Médecine]. Parakou: Université de Parakou, Faculté de médecine; 2017.

[5] Bako H, Doddo Siddo M N, Garba M, Dan Aouta M, Hankarao O. Aspects épidémiologiques, cliniques, para cliniques et étiologiques des patients admis pour affections douloureuses thoraciques d'origine cardiaque: étude prospective multicentrique à propos de 102 cas. Cardiologie Tropicale. 2013; $\mathrm{N}^{\circ} 139$.

[6] Adoubi K A, Diby F, Ouattara P, Gnaba A, Ayegnon A, Meneas $\mathrm{C}$, Yangni-Angate $\mathrm{H}$. Les urgences cardiovasculaires du sujet âgé au CHU de Bouaké (côte d'ivoire). Cardiologie Tropicale. 2016; $\mathrm{N}^{\circ} 143$.

[7] Millaire A, de Groote P, Decoulx E, Leroy O, Ducloux G. Outcome after thrombolytic therapy of nine cases of myopericarditis misdiagnosed as myocardial infarction. Eur Heart J. 1995 Mar; 16 (3): 333-8.

[8] Aida Soufiani, Nesma Bendagha, Nabila Ismaili, H. Bouzelmat, Houda Benjelloun, Fedoua El Ouali, Jamila Zarzur. Myocardite aiguë simulant un syndrome coronaire aigu. STV. 2009; 21 (9-10): 485-90.

[9] Bouzerda A. Acute myopericarditis simulating myocardial infarction: report of a case and review of literature. Pan Afr Med J. 2015 May 28; 21: 70.

[10] Nozari Y, Tajdini M, Mehrani M, Ghaderpanah R. Focal Myopericarditis as a Rare but Important Differential Diagnosis of Myocardial Infarction; a Case Series. Emerg (Tehran). 2016 Summer; 4(3): 159-62.

[11] Nisbet BC, Breyer M. Acute myopericarditis with focal ECG findings mimicking acute myocardial infarction. J Emerg Med. 2010 Nov; 39(5):e153-8.
[12] Testani JM, Kolansky DM, Litt H, Gerstenfeld EP. Focal myocarditis mimicking acute ST-elevation myocardial infarction: diagnosis using cardiac magnetic resonance imaging. Tex Heart Inst J. 2006; 33 (2): 256-9.

[13] Chaudhari M, Sharma S, Jha RK, Ahuja RS, Bansal S. Varicella myopericarditis mimicking acute myocardial infarction with ARDS - A rare association in an immunocompetent young adult. Indian Heart J. 2016 Sep; 68 Supp1 2: S274-S275.

[14] Tipoo Sultan FA, Adnan G. Myocarditis mimicking acute coronary syndrome - the role of cardiac magnetic resonance imaging in the diagnosis. J Pak Med Assoc. 2018 Mar; 68 (3):477-479.

[15] Jbeli AH, Anuwatworn A, Petrasko MS. Myocarditis mimicking acute coronary syndrome: the role of cardiac magnetic resonance imaging and immunoglobulin therapy. Am J Emerg Med. 2015 Nov; 33(11):1717. e3-4.

[16] Shahid M, Hoey E, Basavarajaiah S. Acute Myocarditis and ST-Segment Elevation. Am J Cardiol. 2016 Nov 15; 118 (10):1605-08

[17] Sharma J, Fernandes N, Alvarez D, Khanna S. Acute myopericarditis in an adolescent mimicking acute myocardial infarction. Pediatr Emerg Care. 2015 Jun; 31 (6):427-30.

[18] Skouri HN, Dec GW, Friedrich MG, Cooper LT. Noninvasive imaging in myocarditis. J Am Coll Cardiol. 2006 Nov 21; 48 (10):2085-93.

[19] Felker GM, Boehmer JP, Hruban RH, et al. Echocardiographic findings in fulminant and acute myocarditis. J Am Coll Cardiol. $2000 \mathrm{Jul} ; 36$ (1):227-32. 